Original article

\title{
Schizophrenia patients with high intelligence: A clinically distinct sub-type of schizophrenia?
}

\author{
E. Černis ${ }^{\text {a,* }}$, E. Vassos ${ }^{\text {a }}$, G. Brébion ${ }^{\text {b }}$, P.J. McKenna ${ }^{c}$, R.M. Murray ${ }^{a}$, A.S. David ${ }^{\text {a }}$, \\ J.H. MacCabe ${ }^{a}$ \\ a Department of Psychosis Studies, Institute of Psychiatry, King's College London, Box P063, De Crespigny Park, London, United Kingdom, SE5 8AF \\ ${ }^{\mathrm{b}}$ Unit of Research and Development, Parc Sanitari Sant Joan de Déu and CIBERSAM, Barcelona, Spain \\ ${ }^{\mathrm{c}}$ Benito Menni CASM, and CIBERSAM, Barcelona, Spain
}

\section{A R T I C L E I N F O}

\section{Article history:}

Received 6 November 2014

Received in revised form 9 February 2015

Accepted 11 February 2015

Available online $\mathrm{xxx}$

\section{Keywords:}

Schizophrenia

Psychosis

IQ

Cognitive function

Superphrenia

\begin{abstract}
A B S T R A C T
Background: Schizophrenia patients are typically found to have low IQ both pre- and post-onset, in comparison to the general population. However, a subgroup of patients displays above average IQ preonset. The nature of these patients' illness and its relationship to typical schizophrenia is not well understood. The current study sought to investigate the symptom profile of high-IQ schizophrenia patients.

Methods: We identified 29 schizophrenia patients of exceptionally high pre-morbid intelligence (mean estimated pre-morbid intelligence quotient (IQ) of 120), of whom around half also showed minimal decline (less than 10 IQ points) from their estimated pre-morbid IQ. We compared their symptom scores (SAPS, SANS, OPCRIT, MADRS, GAF, SAI-E) with a comparison group of schizophrenia patients of typical IQ using multinomial logistic regression.

Results: The patients with very high pre-morbid IQ had significantly lower scores on negative and disorganised symptoms than typical patients $(\mathrm{RRR}=0.019 ; 95 \% \mathrm{CI}=0.001,0.675, P=0.030)$, and showed better global functioning and insight ( $R R R=1.082 ; 95 \% C I=1.020,1.148 ; P=0.009$ ). Those with a minimal post-onset IQ decline also showed higher levels of manic symptoms (RRR $=8.213 ; 95 \%$ $\mathrm{CI}=1.042,64.750, P=0.046$ ).

Conclusions: These findings provide evidence for the existence of a high-IQ variant of schizophrenia that is associated with markedly fewer negative symptoms than typical schizophrenia, and lends support to the idea of a psychosis spectrum or continuum over boundaried diagnostic categories.
\end{abstract}

(c) 2015 Published by Elsevier Masson SAS.

\section{Introduction}

Cognitive deficits are consistently found in schizophrenia patients, detectable several years before psychosis onset, and it has been suggested that this impairment constitutes a core feature of schizophrenia [18] and reflects aberrant neurodevelopment [9]. A recent meta-analytic review of IQ in schizophrenia concluded that a deficit of around half of a standard deviation (Cohen's $d=0.54$ ) is present prior to schizophrenia onset, with evidence of additional deterioration around the time of transition to psychosis [32].

\footnotetext{
* Corresponding author at: University of Oxford Institute of Clinical Psychology Training, Isis Education Centre, Warneford Hospital, Oxford, OX3 7JX. Tel.: +44 7792051130

E-mail address: Emma.cernis@hmc.ox.ac.uk (E. Černis).
}

However, there is evidence that some patients with schizophrenia have normal or even enhanced cognitive function [11,15,21]. The nature of these patients' illness and its relationship to typical schizophrenia is not well understood. It has previously been suggested that schizophrenia with high IQ may be a distinct syndrome or disorder with a different aetiology to typical schizophrenia [21,19], and a recent report suggests that schizophrenia without neuropsychological abnormalities may be associated with less white matter pathology than typical schizophrenia [31].

If schizophrenia with high IQ has a different aetiology than typical schizophrenia, we would expect there to be a systematic difference in clinical presentation. Previous research has found that schizophrenia patients with high IQ differed in two respects from typical patients: they had a predominance of affective symptoms and fewer negative symptoms [19]. This excess of affective symptoms is in line with research showing that 
non-affected twins carrying genes conferring risk for bipolar affective disorder demonstrate enhanced neurocognitive functioning [12] and research showing that excellent school performance is associated with increased risk for bipolar affective disorder [20], but is protective against schizophrenia [18].

Negative and disorganised symptom dimensions have frequently been associated with poor cognitive function. It has been shown that cognitively intact patients displayed significantly less severe negative symptoms [16,2], while other research has found that both negative and disorganized symptom dimensions were negatively correlated with IQ [8]. Positive symptoms, on the other hand, appear to be relatively independent of cognitive function $[2,8]$. Lastly, insight has been shown to be positively correlated with IQ [1].

Several researchers have suggested that schizophrenia patients with normal intellectual performance may actually have declined from superior pre-morbid levels, and indeed, previous research has shown examples of this [15]. However, if it were to be found that some patients do not show such a decline, it would be reasonable to suggest that they may be etiologically distinct from those who do show a discrepancy between pre-morbid and current IQ estimates.

Recently, neuropsychological findings were reported from a group of individuals with schizophrenia who had a mean estimated pre-morbid IQ of 120 [21]. In this study, the symptom profile of this sample of patients was compared with that of a comparison sample of typical schizophrenia patients, assessed at the same time. They further divided high-IQ participants into two subgroups: those showing a decline from pre-morbid levels, and those not showing this pattern, in order to investigate any potential differences in symptomatology between these two groups.

Using data collected by this research [21], we hypothesised that the patients with high pre-morbid IQ would show more affective symptoms, fewer negative symptoms, better insight and better functional outcome than typical patients with schizophrenia.

\section{Method}

\subsection{Design}

Case-control study.

\subsection{Participants}

Participants were recruited via research and clinical programs at the Institute of Psychiatry (King's College London) and the University of Cambridge and their associated clinical services (the South London and Maudsley NHS Foundation Trust and the Cambridge shire and Peterborough NHS Foundation Trust). HighIQ patients were actively sought out by examining IQ scores from previous research participants, and through regular requests to clinical colleagues to refer patients with high neurocognitive scores and/or an educational history (for example, postgraduate qualifications) indicating their likelihood to meet the inclusion criteria described below.

Patients were included if they had a diagnosis of schizophrenia or schizoaffective disorder according to DSM-IV criteria, with an estimated pre-morbid IQ of $\geq 115$, aged between 18 and 65 years, with no concurrent substance misuse, capacity to give informed consent, and English as their first language. We also recruited a comparison group, from the same set of research and clinical populations, of schizophrenia patients with an estimated premorbid IQ $\leq 110$.

We approached 59 potential high-IQ patients. Of these, 19 declined to participate or did not meet inclusion criteria and
11 participated but could not be included in this analysis due to missing data. Therefore, 29 high-IQ patients participated. The total number of participants included in the study was 43 after the inclusion of 14 control patients.

Twenty-nine high-IQ participants contributed data to the study, all of whom demonstrated an estimated pre-morbid IQ of at least one standard deviation above the population mean (IQ $\geq 115$ ). Premorbid IQ was estimated using the re-standardised version of the National Adult Reading Test (NART) [24].

The high-IQ group was further subdivided into two subgroups: the "high intact" (HI) group, who showed a decline of less than 10 points in IQ score from their estimated pre-morbid to their current IQ $(n=10)$; and the remainder, who constituted the "high decline" (HD) group $(n=19)$. Current IQ was estimated using Wechsler Adult Intelligence Scale, version III (WAIS-III) [30].

The typical IQ group was made up of patients with an estimated pre-morbid IQ below 110, regardless of current IQ $(n=14)$. This group was recruited from the same research and clinical services as the high-IQ cases, using the same methods and diagnostic criteria.

The demographic details of the three groups are shown in Table 1.

\subsection{Clinical assessment}

We assessed all participants using the following structured interview schedules: The Diagnostic Interview for Genetic Studies (DIGS) [25] - a clinical interview allowing the diagnosis of schizophrenia by DSM-IV criteria, and containing items from the OPCRIT checklist (Operational Criteria Checklist for Psychotic Illness) [22] which assesses lifetime symptomatology.

We assessed current symptoms using three symptom scales: the Scale for the Assessment of Negative Symptoms (SANS) [4], Scale for the Assessment of Positive Symptoms (SAPS) [5]; and the Montgomery-Åsberg Depression Rating Scale (MADRS) [23]. The Global Assessment of Functioning Scale (GAF, as listed in the DSMIV-TR) [10] was used to rate participants' social, occupational and psychological functioning over the month prior to the data collection interview. We assessed insight using the Schedule for the Assessment of Insight - Expanded Version (SAI-E) [13].

Pre-morbid IQ was estimated by means of the NART. Current IQ was estimated using subtests of the WAIS-III [30]: vocabulary, similarities, digit span, letter-number sequencing, arithmetic, picture completion, picture arrangement and matrix reasoning.

Table 1

Clinical and demographic information for the three participant groups.

\begin{tabular}{|c|c|c|c|}
\hline & Typical (T) & $\begin{array}{l}\text { High } \\
\text { decline } \\
\text { (HD) }\end{array}$ & $\begin{array}{l}\text { High } \\
\text { intact } \\
(\mathrm{HI})\end{array}$ \\
\hline$n$ (male \%) & $14(86 \%)$ & $19(68 \%)$ & $10(60 \%)$ \\
\hline \multirow[t]{3}{*}{$\begin{array}{l}\text { Diagnoses (schizophrenia: } \\
\text { schizoaffective disorder) }\end{array}$} & $13: 1$ & $16: 3$ & $9: 1$ \\
\hline & Typical (T) & $\begin{array}{l}\text { High decline } \\
\text { (HD) }\end{array}$ & $\begin{array}{l}\text { High intact } \\
\text { (HI) }\end{array}$ \\
\hline & Mean (SD) & Mean (SD) & Mean (SD) \\
\hline Age (yrs) & $35.0(10.9)$ & $41.6(10.8)$ & $36.5(8.0)$ \\
\hline IQ NART & $101.3(9.6)$ & $120.2(3.4)$ & $119.9(2.8)$ \\
\hline Range & $(86-112)$ & $(115-127)$ & $(116-124)$ \\
\hline IQ WAIS-III & $91.0(12.9)$ & $102.6(7.2)$ & $116.7(5.4)$ \\
\hline Range & $(74-117)$ & $(87-113)$ & $(108-124)$ \\
\hline Years of education & $12.4(2.7)$ & $14.0(2.6)$ & $16.4(2.2)$ \\
\hline $\begin{array}{l}\text { Age of onset of } \\
\text { schizophrenia }\end{array}$ & $19.7(7.9)$ & $20.5(4.7)$ & $18.2(11.4)$ \\
\hline
\end{tabular}

Showing the means and standard deviations for: numbers of participants (and percentage of males), proportion of diagnoses in each group, mean age, estimated pre-morbid IQ, post-onset IQ, mean years of education and mean age of illness onset for each group. 
The neuropsychological testing is described more fully by MacCabe et al. [21].

\subsection{Statistical analysis}

In order to more usefully analyse the DIGS/OPCRIT variables, they were aggregated into factors. Since this sample was not sufficiently large to achieve this via factor analysis, regression coefficients from a previous factor analysis of OPCRIT variables were used [29]. This sample comprised 1545 individuals with a diagnosis of schizophrenia recruited from London, UK and Utrecht, Netherlands for a large family study of symptom dimensions. Principal Component Analysis (PCA) with Varimax rotation of 44 OPCRIT items generated four factors: Manic, Depressive, Positive and Negative-Disorganised symptoms.

Multinomial logistic regression was carried out in order to determine whether lifetime symptom profile, current symptoms or functional outcome could differentiate between IQ groups. Three multinomial logistic regression analyses were performed: one including the four lifetime symptom factors derived from DIGS/OPCRIT (Manic, Positive, Negative-Disorganised and Depressive); the second using current symptomatology (SANS, SAPS, MADRS), and the third using the global assessment of function (GAF) score alone. All analyses were also adjusted for age and sex. The Typical group was the reference group throughout.

\subsection{Ethics approval}

The study was approved by the ethics committee of the Institute of Psychiatry, and all participants gave written, informed consent. All data was recorded anonymously and stored in accordance with data protection guidelines.

\section{Results}

The means and standard deviations for all variables are shown in Table 2.

The results of the multinomial logistic regression analysis (Table 3 ) indicated that the HI group differed from the T group on the variables of the OPCRIT negative-disorganised factor, SANS, GAF and SAI-E. The HD and T groups differed on SANS and OPCRIT Manic factor scores.

The Relative Risk Ratio (RRR) indicates that with one unit increase in the named variable, the relative risk of belonging to the named group as opposed to the Typical group increases by the figure stated.

For example, the Manic factor was a significant predictor of being in the 'high decline' rather than the Typical group $(\mathrm{RRR}=8.213 ; 95 \% \mathrm{CI}=1.042,64.750, P=0.046)$. Thus, one unit change in the "Manic" factor was associated with an increase in the relative risk of belonging to the "high decline" group compared to the "Typical" group of 8.21. The Negative-Disorganised factor was found to significantly predict membership of the Typical as opposed to the HI group ( $R R R=0.019 ; 95 \% \mathrm{CI}=0.001,0.675$, $P=0.030$ ). It should be noted that a unit change in either of these OPCRIT factors represents a substantial change, of the order of two standard deviations-see Table 2 for the means and standard deviations of each measure.

A lower SANS score was a significant predictor of being in the $\mathrm{HI}$ or the HD groups. (HI vs. Typical: $\mathrm{RRR}=0.901 ; 95 \% \mathrm{CI}=0.830$, $0.977, P=0.012$. HD vs. Typical: $\mathrm{RRR}=0.954 ; 95 \% \mathrm{CI}=0.912,0.998$, $P=0.042$ ).

Lower GAF scores were increasingly likely to be associated with the HI group, $(\mathrm{RRR}=1.082 ; 95 \% \mathrm{CI}=1.020,1.148 ; P=0.009)$.

The SAI-E scores appear to delineate the three groups: firstly, the $\mathrm{HI}$ group $(\mathrm{RRR}=1.083 ; 95 \% \mathrm{CI}=1.042,1.158 ; P=0.021$ ), and secondly, there is a borderline significant result indicating that a unit increase in the SAI-E increases the chance of being the HD as opposed to Typical group ( $R R R=1.066 ; 95 \% C I=0.998,1.138$; $P=0.057$ ). This suggests that the HI group has the highest level of insight, followed by the HD group, and then the Typical group, following the pattern in the mean scores for SAI-E presented in Table 2.

\section{Discussion}

In this sample of schizophrenia patients of exceptionally high pre-morbid IQ, we found substantial differences in scores on current and lifetime symptoms, compared with a comparison group of typical schizophrenia patients. Our hypothesis that patients with high pre-morbid IQ would show more affective symptoms, fewer negative symptoms, better insight and better functional outcome than typical patients with schizophrenia was supported by the data.

\subsection{Limitations}

This study is limited by its small sample size. In particular, it is possible that the numerically substantial differences in scores for the affective dimensions failed to reach significance because of a lack of statistical power. However, the relatively small sample of high-IQ patients is a consequence of the uniqueness of this sample. Identifying the 59 schizophrenia patients with a NART of $>115$ involved a systematic search for such patients in two major academic centres. While other studies have examined schizophrenia patients of normal intellectual functioning, we are not aware of any other sample of schizophrenia patients with such high IQ.

Table 2

Means and standard deviations for each measure by participant group.

\begin{tabular}{|c|c|c|c|}
\hline & Typical (T) & High decline (HD) & High intact $(\mathrm{HI})$ \\
\hline & Mean (SD) & Mean (SD) & Mean (SD) \\
\hline OPCRIT Lifetime Manic factor & $0.016(0.462)$ & $0.474(0.524)$ & $0.296(0.552)$ \\
\hline OPCRIT Lifetime Depressive factor & $0.647(0.524)$ & $1.020(0.575)$ & $1.129(0.539)$ \\
\hline OPCRIT Lifetime Positive factor & $0.826(0.406)$ & $0.933(0.349)$ & $0.774(0.466)$ \\
\hline OPCRIT Lifetime Negative-Disorganised factor & $0.768(0.351)$ & $0.773(0.369)$ & $0.490(0.319)$ \\
\hline SAPS & $26.571(13.998)$ & $20.889(21.091)$ & $18.900(25.305)$ \\
\hline SANS & $58.714(28.564)$ & $37.278(20.396)$ & $21.000(16.826)$ \\
\hline MADRS & $8.143(7.167)$ & $7.556(8.155)$ & $3.000(2.062)$ \\
\hline GAF & $43.643(16.932)$ & $53.611(19.614)$ & $67.000(17.029)$ \\
\hline SAI-E & $30.571(12.439)$ & $45.474(31.283)$ & $66.800(51.201)$ \\
\hline
\end{tabular}

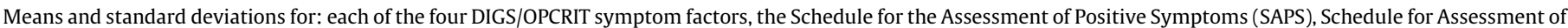

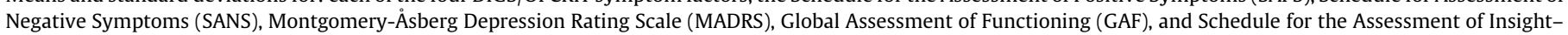
Expanded version (SAI-E). 
Table 3

Group differences in symptom factors.

\begin{tabular}{|c|c|c|c|c|c|}
\hline Factor/Variable & Groups & $\begin{array}{l}\text { RRR } \\
\text { (relative } \\
\text { risk ratio) }\end{array}$ & $P$ & $\begin{array}{l}95 \% \\
\text { Confidence } \\
\text { interval }\end{array}$ & $\begin{array}{l}\text { Standard } \\
\text { error }\end{array}$ \\
\hline OPCRIT Lifetime Manic factor & $\begin{array}{l}\text { HD vs. T } \\
H I \text { vs. } T\end{array}$ & $\begin{array}{l}\mathbf{8 . 2 1 3} \\
3.297\end{array}$ & $\begin{array}{l}\mathbf{0 . 0 4 6} \\
0.297\end{array}$ & $\begin{array}{c}\mathbf{1 . 0 4 2 ,} \mathbf{6 4 . 7 5 0} \\
0.350,31.079\end{array}$ & $\begin{array}{l}\mathbf{8 . 6 5 2} \\
3.774\end{array}$ \\
\hline OPCRIT Lifetime Depressive factor & $\begin{array}{l}H D \text { vs. } T \\
H I \text { vs. } T\end{array}$ & $\begin{array}{l}1.437 \\
7.140\end{array}$ & $\begin{array}{l}0.670 \\
0.069\end{array}$ & $\begin{array}{l}0.271,7.632 \\
0.861,59.210\end{array}$ & $\begin{array}{l}1.224 \\
7.706\end{array}$ \\
\hline OPCRIT Lifetime Postive factor & $\begin{array}{l}\text { HD vs. T } \\
H I \text { vs. } T\end{array}$ & $\begin{array}{l}4.770 \\
1.034\end{array}$ & $\begin{array}{l}0.210 \\
0.980\end{array}$ & $\begin{array}{l}0.415,54.832 \\
0.076,14.020\end{array}$ & $\begin{array}{l}5.943 \\
1.375\end{array}$ \\
\hline $\begin{array}{l}\text { OPCRIT Lifetime } \\
\text { Negative-Disorganised factor }\end{array}$ & $\begin{array}{l}\text { HD vs. T } \\
\text { HI vs. T }\end{array}$ & $\begin{array}{l}0.448 \\
0.019\end{array}$ & $\begin{array}{l}0.541 \\
\mathbf{0 . 0 3 0}\end{array}$ & $\begin{array}{c}0.034,5.863 \\
\mathbf{0 . 0 0 1}, \mathbf{0 . 6 7 5}\end{array}$ & $\begin{array}{l}0.588 \\
0.035\end{array}$ \\
\hline SANS & $\begin{array}{l}\text { HD vs. T } \\
\text { HI vs. T }\end{array}$ & $\begin{array}{l}0.954 \\
0.901\end{array}$ & $\begin{array}{l}0.042 \\
0.012\end{array}$ & $\begin{array}{l}0.912,0.998 \\
0.830,0.977\end{array}$ & $\begin{array}{l}0.022 \\
0.037\end{array}$ \\
\hline SAPS & $\begin{array}{l}H D \text { vs. } T \\
H I \text { vs. T }\end{array}$ & $\begin{array}{l}1.016 \\
1.066\end{array}$ & $\begin{array}{l}0.564 \\
0.110\end{array}$ & $\begin{array}{l}0.962,1.074 \\
0.986,1.154\end{array}$ & $\begin{array}{l}0.028 \\
0.043\end{array}$ \\
\hline MADRS & $\begin{array}{l}\text { HD vs. T } \\
\text { HI vs. T }\end{array}$ & $\begin{array}{l}1.012 \\
0.853\end{array}$ & $\begin{array}{l}0.857 \\
0.205\end{array}$ & $\begin{array}{l}0.889,1.152 \\
0.668,1.090\end{array}$ & $\begin{array}{l}0.067 \\
0.107\end{array}$ \\
\hline GAF (previous month) & $\begin{array}{l}H D \text { vs. } T \\
\text { HI vs. T }\end{array}$ & $\begin{array}{l}1.041 \\
1.082\end{array}$ & $\begin{array}{l}0.108 \\
0.009\end{array}$ & $\begin{array}{c}0.991,1.093 \\
\mathbf{1 . 0 2 0}, \mathbf{1 . 1 4 8}\end{array}$ & $\begin{array}{l}0.026 \\
0.033\end{array}$ \\
\hline SAI-E & $\begin{array}{l}H D \text { vs. } T \\
\text { HI vs. } \mathbf{T}\end{array}$ & $\begin{array}{l}1.066 \\
\mathbf{1 . 0 8 3}\end{array}$ & $\begin{array}{l}0.057 \\
\mathbf{0 . 0 2 1}\end{array}$ & $\begin{array}{c}0.998,1.138 \\
\mathbf{1 . 0 4 2 ,} \mathbf{1 . 1 5 8}\end{array}$ & $\begin{array}{l}0.036 \\
0.037\end{array}$ \\
\hline
\end{tabular}

Statistics for the logistic regression results-adjusted for age and sex.

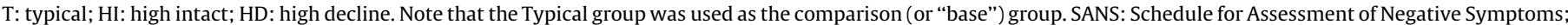

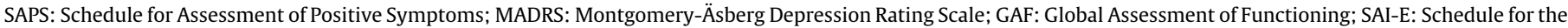
Assessment of Insight - Expanded Version.

Significant results are shown in bold, and non-significant results in italics.

Please see results section for interpretation of RRRs.

\subsection{Negative symptoms}

The most marked difference between the groups was in the prevalence of negative symptoms. The two high-IQ groups scored much lower than typical patients on negative symptoms at the time of interview (SANS) and the high intact group scored much lower in a negative/disorganised factor derived from OPCRIT scores over the history of their illness.

Previous studies have found associations between levels of neurocognitive impairment and greater severity of negative symptoms [27], with one study finding that participants with a 'negative syndrome' had a mean IQ of 88.88 despite all participants having at least high school level education and similar socioeconomic status [7]. Longitudinal studies also support such an association: lower IQ has been found to predict more negative symptoms at a one year follow up [6], the presence of a negative symptom syndrome after four years [17], and similarly after a ten year follow up [28]. While these previous studies demonstrated that negative symptoms correlate with IQ over the middle of the IQ spectrum, this study indicates that this relationship persists into the highest levels of IQ.

\subsection{Affective symptoms}

There was evidence of increased manic symptomatology in both High-IQ groups, although this was only significant for the HD group. There was evidence that high-IQ patients had more depressive symptoms during their lifetime than typical patients; although this failed to reach significance. Moreover, there was an interesting dissociation between lifetime depressive symptoms (depressive factor on OPCRIT) and current depressive symptoms (MADRS), whereby the high intact patients scored highest on lifetime depressive symptoms but lowest on depressive symptoms at the time of testing (Table 2). This suggests that, while depressive symptoms are a prominent clinical feature in high-intact patients when they are unwell, their better functional outcomes may give rise to a greater respite from depressive symptomatology than patients with typical schizophrenia.

\subsection{Positive symptoms}

There were no significant differences in lifetime or current positive symptoms between the groups. This is perhaps not surprising, since the presence of positive symptoms is considered a core feature of schizophrenia and would therefore be expected in all participant groups where a diagnosis of schizophrenia has been assigned.

\subsection{Insight}

Insight was best in the high intact group, intermediate in the high decline group, and poorest in the Typical group, although only the HI group differed significantly. This confirms that the association between IQ and insight [1] persists into the superior IQ range.

\subsection{Evidence for a 'superphrenia' syndrome}

The results of the current study are strikingly similar to those of previous work demonstrating that schizophrenia patients with university education showed a similar pattern of fewer negative and more depressive symptoms [19].

Such results could be argued to constitute evidence for a separate syndrome, characterised by high pre-morbid IQ and a clinical profile featuring predominantly positive and affective symptoms, few negative and disorganised symptoms, good insight and good global functioning [21]. We offer the term 'superphrenia' to describe this syndrome. 
Recently, several studies have demonstrated sharp contrasts in cognitive functioning and educational attainment between schizophrenia and bipolar disorder, suggesting that cognitive function is a strong discriminator between the two disorders $[9,14]$. However, 'superphrenia' appears to be anomalous. It has been suggested before [21] that what we term here as 'superphrenia' could have more in common with bipolar disorder than schizophrenia. Indeed, it has been found that cognitively intact schizophrenia patients are much more likely to have a diagnosis of schizoaffective disorders than cognitively impaired patients [2]. Whether 'superphrenia' is conceptualised as a separate syndrome, or as occupying a position on a psychosis spectrum between bipolar affective disorder and typical IQ schizophrenia, is a moot point. The existence of a clinically distinct subgroup of schizophrenia patients, such as 'superphrenia' individuals, however, does highlight the heterogeneity of presentations, which attract a formal diagnosis of 'schizophrenia', and as such lends support to the idea of a psychosis spectrum or continuum over the established boundaried diagnostic categories.

There is some evidence for neuroanatomical differences between patients with normal versus impaired cognitive function. In a study of brain morphometry, neuropsychologically impaired schizophrenia patients had significantly reduced grey and white matter volumes and enlarged ventricles, as is typically found in schizophrenia. The neuropsychologically normal schizophrenia group, however, had normal white matter volumes and lateral ventricular volumes [31]. These data are consistent with studies showing that deficits in cognitive functioning in first episode schizophrenia are associated with reductions in white matter integrity [26]. The similarity between superphrenia and bipolar disorder is supported by recent findings showing a similar pattern, with grey matter deficits common to both bipolar disorder and schizophrenia, but white matter abnormalities observed in schizophrenia alone [3].

In conclusion, the current study has provided further evidence of a distinct schizophrenia subgroup of 'superphrenia' individuals, whose schizophrenia is characterised by high pre-morbid IQ better global functioning, better insight, fewer negative and disorganised and more affective symptoms than typical schizophrenia.

\section{Disclosure of interest}

The authors declare that they have no conflicts of interest concerning this article.

\section{Acknowledgements}

This study presents independent research part-funded by the National Institute for Health Research (NIHR) Biomedical Research Centre at South London and Maudsley NHS Foundation Trust and King's College London. The views expressed are those of the author(s) and not necessarily those of the NHS, the NIHR or the Department of Health.

\section{References}

[1] Aleman A, Agrawal N, Morgan KD, David AS. Insight in psychosis and neuropsychological function: meta-analysis. Brit J Psychiatry 2006;189:204-12.

[2] Ammari N, Heinrichs RW, Miles AA. An investigation of 3 neurocognitive subtypes in schizophrenia. Schizophr Res 2010;121(1-3):32-8.

[3] Anderson D, Ardekani BA, Burdick KE, Robinson DG, John M, Malhotra AK, et al Overlapping and distinct grey and white matter abnormalities in schizophrenia and bipolar I disorder. Bipolar Disord 2013;15(6):680-93.

[4] Andreasen N. Scale for the assessment of negative symptoms (SANS). University of Iowa; 1984.
[5] Andreasen N. Scale for the assessment of positive symptoms (SAPS). University of Iowa; 1984

[6] Carlsson R, Nyman H, Ganse G, Cullberg J. Neuropsychological functions predict 1- and 3-year outcome in first-episode psychosis. Acta Psychiatr Scand 2006;113(2):102-11

[7] Cvetić T, Vuković O. Cognitive deficit in schizophrenia: comparative analysis of positive and negative subtype and predictors of positive subtype. Psychiatr Danub 2006;18(1-2):4-11.

[8] de Gracia Dominguez M, Viechtbauer W, Simons CJP, van Os J, Krabbendam L. Are psychotic psychopathology and neurocognition orthogonal? A systematic review of their associations. Psychol Bull 2009;135(1):157-71.

[9] Demjaha A, MacCabe JH, Murray RM. How genes and environmental factors determine the different neurodevelopmental trajectories of schizophrenia and bipolar disorder. Schizophr Bull 2012;38(2):209-14.

[10] Endicott J, Spitzer RL, Fleiss JL, Cohen J. The global assessment scale. A procedure for measuring overall severity of psychiatric disturbance. Arch Gen Psychiatry 1976;33(6):766-71

[11] Heinrichs W, Ammari N, McDermid Vaz S, Miles A, Muharib E. Above average intellectual ability and functional status in schizophrenia. Schizophr Bull 2011;267 [Conference: 13th International Congress on Schizophrenia Research, ICOSR Colorado Springs, CO United States. Conference Start: 20110402 Conference End: 20110406. Conference Publication: 37].

[12] Higier RG, Jimenez AM, Hultman CM, Borg J, Roman C, Kizling I, et al. Enhanced neurocognitive functioning and positive temperament in twins discordant for bipolar disorder. Am J Psychiatry 2014;171(11):1191-8.

[13] Kemp R, David A. Insight and compliance. In: Blackwell, editor. Compliance and the treatment alliance in serious mental illness. Amsterdam: Hardwood Academic Publishers; 1997. p. 61-86.

[14] Koenen KC, Moffitt TE, Roberts AL, Martin LT, Kubzansky L, Harrington H, et al. Childhood IQ and adult mental disorders: a test of the cognitive reserve hypothesis. Am J Psychiatry 2009;166(1):50-7.

[15] Kremen WS, Seidman LJ, Faraone SV, Toomey R, Tsuang MT. The paradox of normal neuropsychological function in schizophrenia. J Abnorm Psychol 2000;109(4):743-52

[16] Leeson VC, Barnes TRE, Hutton SB, Ron MA, Joyce EM. IQ as a predictor of functional outcome in schizophrenia: a longitudinal, four-year study of firstepisode psychosis. Schizophr Res 2009;107(1):55-60.

[17] Leeson VC, Sharma P, Harrison M, Ron MA, Barnes TR, Joyce EM. IQ trajectory, cognitive reserve, and clinical outcome following a first episode of psychosis: a 3-year longitudinal study. Schizophr Bull 2011;37(4):768-77.

[18] MacCabe JH. Population-based cohort studies on premorbid cognitive function in schizophrenia. Epidemiol Rev 2008;30:77-83.

[19] MacCabe JH, Aldouri E, Fahy TA, Sham PC, Murray RM. Do schizophrenic patients who managed to get to university have a non-developmental form of illness? Psychol Med 2002;32:535-44

[20] MacCabe JH, Lambe MP, Cnattingius S, Sham PC, David AS, Reichenberg A, et al. Excellent school performance at age 16 and risk of adult bipolar disorder: national cohort study. Br J Psychiatry 2010;196:109-15.

[21] MacCabe JH, Brébion G, Reichenberg A, Ganguly T, McKenna PJ, Murray RM, et al. Superior intellectual ability in schizophrenia: neuropsychological characteristics. Neuropsychology 2012;26(2):181-90.

[22] McGuffin P, Farmer A, Harvey I. A polydiagnostic application of operational criteria in studies of psychotic illness: development and reliability of the OPCRIT system. Arch Gen Psychiatry 1991;48(8):764-70.

[23] Montgomery SA, Asberg M. A new depression scale designed to be sensitive to change. Br J Psychiatry 1979;134(4):382-9.

[24] Nelson HE, Willison JR. The revised national adult reading test-test manual. Windsor, UK: NFER-Nelson; 1991.

[25] Nurnberger JI, Blehar MC, Kaufmann CA, York-Cooler C, Simpson SG, HarkavyFriedman J, et al. Diagnostic interview for genetic studies: rationale, unique features, and training. Arch Gen Psychiatry 1994;51(11):849-59.

[26] Perez-Iglesias R, Tordesillas-Gutierrez D, McGuire PK, Barker GJ, Roiz-Santianez R, Mata I, et al. White matter integrity and cognitive impairment in firstepisode psychosis. Am J Psychiatry 2010;167(4):451-8.

[27] Russo M, Kravariti E, Demjaha A, Dazzan P, Morgan C, Murray RM, et al. The relationship between neuropsychological functioning and symptom dimensions in first-episode psychosis. Schizophr Res 2010 [Conference: 2nd Schizophrenia International Research Society Conference, SIRS 2010 Florence Italy. Conference Start: 20100410 Conference End: 20100414. Conference Publication:117(2-3):175-6].

[28] Stirling J, White C, Lewis S, Hopkins R, Tantam D, Huddy A, et al. Neurocognitive function and outcome in first-episode schizophrenia: a 10-year follow-up of an epidemiological cohort. Schizophr Res 2003;65(2-3): 75-86

[29] Vassos E. Narrowing the schizophrenia phenotype: a twin study of symptom dimensions. In: Conference: 18th World Congress on Psychiatric Genetics; 2010.

[30] Wechsler D. Wechsler adult intelligence scale, 3rd ed., San Antonio: TX: The Psychological Corporation; 1997.

[31] Wexler BE, Zhu H, Bell MD, Nicholls SS, Fulbright RK, Gore JC, et al. Neuropsychological near normality and brain structure abnormality in schizophrenia. Am J Psychiatry 2009;166(2):189-95.

[32] Woodberry KA, Giuliano AJ, Seidman LJ. Premorbid IQ in schizophrenia: a meta-analytic review. Am J Psychiatry 2008;165(5):579-87. 